\title{
Raf kinase inhibitor protein regulates oxygen- glucose deprivation-induced PC12 cells apoptosis through the NF-KB and ERK pathways
}

\author{
Li Su, ${ }^{\dagger}$ Hongli Du, ${ }^{\dagger}$ Xin Dong, Xiuhua Zhang* and Ziyang Lou* \\ School of Pharmacy, Second Military Medical University, 325 Guo-He Road, Shanghai 200433, China
}

(Received 12 October, 2015; Accepted 21 February, 2016; Published online 10 June, 2016)

Raf-1 kinase inhibitory protein (RKIP) is a critical molecule for cellular responses to stimuli. In this study, we investigated whether RKIP is responsible for neural cell apoptosis induced by oxygen-glucose deprivation (OGD) and explored the role of NF-KB and ERK pathways regulated by RKIP under OGD stimuli. RKIP was overexpressed or knocked down using lentivirus in PC12 cells, which were then challenged by OGD. RKIP overexpression significantly increased the cell viability of OGD cells, and attenuated apoptosis, cell cycle arrest, and reactive oxygen species generation. RKIP knockdown induced reverse effects. Moreover, we found that RKIP interacted with TAK1, NIK, IKK, and Raf-1 and negatively regulated the NF-KB and ERK pathways. RKIP overexpression significantly inhibited IKK, IKB $\alpha$, and P65 phosphorylation in NF-KB pathway and MEK, ERK, and CREB phosphorylation in ERK pathway, respectively. RKIP knockdown induced reverse effects. Furthermore, a NF-кB inhibitor BAY 11-7082 and a MEK inhibitor U0126 blocked the changes caused by RKIP down-regulation after OGD. In conclusion, these results demonstrate that RKIP plays a key role in neural cell apoptosis caused by OGD partly via regulating NF-KB and ERK pathways. The present study may provide new insights into the role of RKIP in ischemic stroke.

Key Words: RKIP, ERK pathway, NF-KB pathway, PC12 cells, OGD

troke is the third leading cause of death in the world and $\checkmark$ ischemic stroke is the major subtype. (1) In ischemic stroke, blood supply to part of the brain is reduced, leading to the brain dysfunction in that area. Oxygen-glucose deprivation (OGD) in the ischemic brain eventually leads to cell death, which was believed to have necrotic features. ${ }^{(2)}$ The in vitro OGD model is widely used to understand the mechanism of modulation in neuronal cell death under ischemic stress. ${ }^{(3)}$ OGD mimics ischemic condition and provides a convenient model to understand disease mechanism and test pharmacological drugs for neuroprotective potency. ${ }^{(4,5)}$

Raf-1 kinase inhibitory protein (RKIP), also known as PEBP-1, is a member of the phosphatidylethanolamine-binding protein (PEBP) family and is widely expressed in tissues in a variety of mammalian species. ${ }^{(6)}$ From the discovery in bovine brain to design as a physiological inhibitor of Raf kinase protein, RKIP has emerged as a key molecule for cellular responses to stimuli. Disruption of RKIP was observed in a variety of pathologies, including cancer, Alzheimer's disease (AD), and acute pancreatitis. Moreover, RKIP plays important roles in many pivotal intracellular signaling cascades that control cellular growth, motility, apoptosis, genomic integrity, and therapeutic resistance. ${ }^{(7)}$ Through physical association with NIK, TAK1, and Raf-1, RKIP negatively regulates the NF- $\kappa B$ and ERK pathways. ${ }^{(8,9)}$ Down-modulation of the NF- $\kappa B$ and ERK pathways inhibit the transcriptional activity of
NF- $\kappa \mathrm{B}, \mathrm{AP}-1$, and CREB transcription factors, which lead to cell apoptosis. ${ }^{(10,11)}$ RKIP has been shown to be a metastasis suppressor gene, related to cell proliferation, differentiation, migration, motility, and mitosis, and involved in neural development, cardiac function, and spermatogenesis..$^{(12-14)}$ These reports suggest RKIP may be an interesting target for individualized treatment and disease specific intervention.

RKIP has multiple neurophysiological roles in brain, including its function in the circadian clock and synaptic plasticity. ${ }^{(15)}$ As a precursor protein to hippocampal cholinergic neurostimulating peptides (HCNP), RKIP influences the synthesis of acetylcholine and development of septal cholinergic neurons, which are important for learning and memory. ${ }^{(16)}$ Moreover, dysregulated RKIP expression contributes to pathophysiological processes in AD. ${ }^{(17)}$ RKIP may participate in neuronal apoptosis and cognitive deficits associated with neurodegenerative diseases. ${ }^{(18)}$ Guo et al. ${ }^{(19)}$ reported that cerebral ischemia-induced association between RKIP and Raf-1 resulted in the inhibition of the ERK signaling cascade through an inhibition of Src-mediated Raf-1 phosphorylation at Tyr340/341 residues, suggesting that RKIP is involved in biphasic phosphorylation of ERK after brain ischemia. However, the precise role of RKIP in ischemic stroke is still not clear.

In the present study, we investigated the potential role of RKIP on ischemic injury in oxygen-glucose deprivation (OGD) model. PC12 cells, a cell line that has been applied widely as an in vitro model system for studying ischemic injury in vitro, ${ }^{(20)}$ was used in this study. Moreover, we studied the regulation of RKIP on NF- $\kappa B$ and ERK signaling pathways in OGD-induced neural cell apoptosis.

\section{Materials and Methods}

Cell culture. The high differentiated rat pheochromocytoma tumor cell line PC12, obtained from the Cell Bank of the Shanghai Institute of Biochemistry \& Cell Biology, Shanghai Institute for Biological Sciences, Chinese Academy of Sciences (Shanghai, China), was cultured in Dulbecco's modified Eagle's medium (DMEM) containing 10\% FBS, $100 \mathrm{U} / \mathrm{ml}$ penicillin, and $100 \mu \mathrm{g} / \mathrm{ml}$ streptomycin with $5 \% \mathrm{CO}_{2}$ at $37^{\circ} \mathrm{C}$ as described previously. ${ }^{(21)}$

OGD. OGD in PC12 cells was performed as described previously. ${ }^{(22)}$ After transfection with RKIP overexpression and shRNA lentivirus for $48 \mathrm{~h}, \mathrm{PC} 12$ cells were subjected to OGD by replacing the medium without glucose. Cultures were switched from the normal feeding medium to the oxygen-depleted, glucosefree medium. Cells were incubated in a hypoxia chamber (BillupsRothenberg, Del Mar, CA) previously flushed for 15 min with 5\%

${ }^{\dagger}$ Both authors contributed equally to this work.

*To whom correspondence should be addressed.

E-mail: louziyang@126.com (ZL); 13764695892@163.com (XZ) 
$\mathrm{CO}_{2} / 95 \% \mathrm{~N}_{2}$. After that, valve was closed and then chamber was incubated for $6 \mathrm{~h}$. At the end of OGD, cells were returned to the normal feeding medium and incubated under normal conditions at $37^{\circ} \mathrm{C}$ for $24 \mathrm{~h}$ for later experiments. Control cultures were maintained under regular oxygen atmospheric conditions.

Cell proliferation assay. PC12 cells proliferation of different processing was determined by WST- 8 assay using Cell Counting Kit-8 (Dojindo, Kumamoto, Japan) as described previously. ${ }^{(21)}$ After treatment, each well was added $10 \mu \mathrm{l}$ of WST-8 $(5 \mathrm{mg} / \mathrm{ml})$ and incubated for another $4 \mathrm{~h}$ at $37^{\circ} \mathrm{C}$. Absorbance was read at $450 \mathrm{~nm}$ using a BioTek Synergy plate reader (BioTek, Winooski, VT). The cell survival percentages were calculated by dividing the mean OD of compound-containing wells by that of control wells.

Apoptosis assay. Cells apoptosis assay was detected using an Annexin V-APC apoptosis detection kit from BD Biosciences as described previously. ${ }^{(22)}$ In this procedure, PC12 cells were collected and washed with phosphate buffer (PBS), then resuspended in Annexin V binding buffer followed by addition of Annexin V-APC and propidium iodide. The samples were incubated in the dark for $5 \mathrm{~min}$ at room temperature and analyzed with a FACS Calibur flow cytometer (BD Biosciences, San Jose, CA). Mean of $\%$ apoptosis index was calculated by combining early apoptosis (annexin $\mathrm{V}^{+} / \mathrm{PI}^{-}$) and late apoptosis (annexin $\mathrm{V}^{+} / \mathrm{PI}^{+}$) events.

Cell cycle assay. Cell cycle analysis was conducted as described previously. ${ }^{(23)}$ Briefly, PC12 cells were washed with PBS and fixed in $70 \%$ ethanol at $4^{\circ} \mathrm{C}$ overnight. After centrifugation $(1,500 \mathrm{~g}, 3 \mathrm{~min})$ and washed with PBS, cells were re-suspended in RNase $(100 \mu \mathrm{g} / \mathrm{ml})$ at $37^{\circ} \mathrm{C}$ for $30 \mathrm{~min}$, and staining with propidium iodide $(50 \mu \mathrm{g} / \mathrm{ml})$ at $37^{\circ} \mathrm{C}$ for $30 \mathrm{~min}$ in the dark. Cell cycle distribution was determined by a FACS Calibur flow cytometer (BD Biosciences, San Jose, CA) and the data were analyzed using ModFit software.

ROS assay. Intracellular superoxide anion/superoxide-derived reactive oxygen species (ROS) was monitored using the fluorescent probe dihydroethidium (DHE, Beyotime Institute of BioTechnology, Haimen, China). Intracellular DHE is oxidized to ethidium, which binds DNA and stains nuclei bright fluorescent red. PC12 cells were treated in the 6-well plates and incubated with a fresh working solution containing $5 \mu \mathrm{M}$ DHE in PBS for $30 \mathrm{~min}$ at $37^{\circ} \mathrm{C}$. After that, $\mathrm{PC} 12$ cells were washed with PBS and conducted using a FACS Calibur flow cytometer (BD Biosciences, San Jose, CA).

Plasmids and transfection. The coding sequence of RKIP and the primers used were generated as described previously. ${ }^{(14)}$ RKIP cDNA was constructed into the vector of IRES-enhanced green fluorescent protein (EGFP) by Shanghai R\&S Biotechnology Co., Ltd. Briefly, the ligated product was transformed into Escherichia coli $\mathrm{DH} 5 \alpha$ cells, coated to LB solid medium, and stored at $37^{\circ} \mathrm{C}$ overnight. The positive clone was incubated in a LB liquid medium with agitation overnight. The recombinant plasmid was extracted and identified for sequencing. The result of DNA sequencing was consistent with the PubMed database. Virus particles were packaged using $293 \mathrm{~T}$ cells with transfection of the above pLenti-RKIP-IRES-EGFP plasmid. After $48 \mathrm{~h}$ transfection, the virus particles were collected and tittered on $293 \mathrm{~T}$ cells as described previously. ${ }^{(24)}$ A multiplicity of infection (MOI) of 20 was used to infect PC12 cells. Transfection efficiency was detected by green fluorescent protein (GFP) as a reporter.

For RNA interference, short hairpin RNA (shRNA) targets of RKIP were designed (GenBank accession no. NM_178812.3) and cloned into pLenti6.3-MCS/V5 DEST lentiviral vector (named pLenti6.3-EGFP-RKIP-microRNA) by Shanghai R\&S Biotechnology Co., Ltd. The infectious lentivirus was produced by transfecting lentivector and packaging vectors into $293 \mathrm{~T}$ cells. Packaging efficiency was assessed by a fluorescence microscopy.

PC12 cells were seeded at a density of $1 \times 10^{5}$ cells in six well plates. At $60 \%$ confluence, the cells were transfected with Lenti-
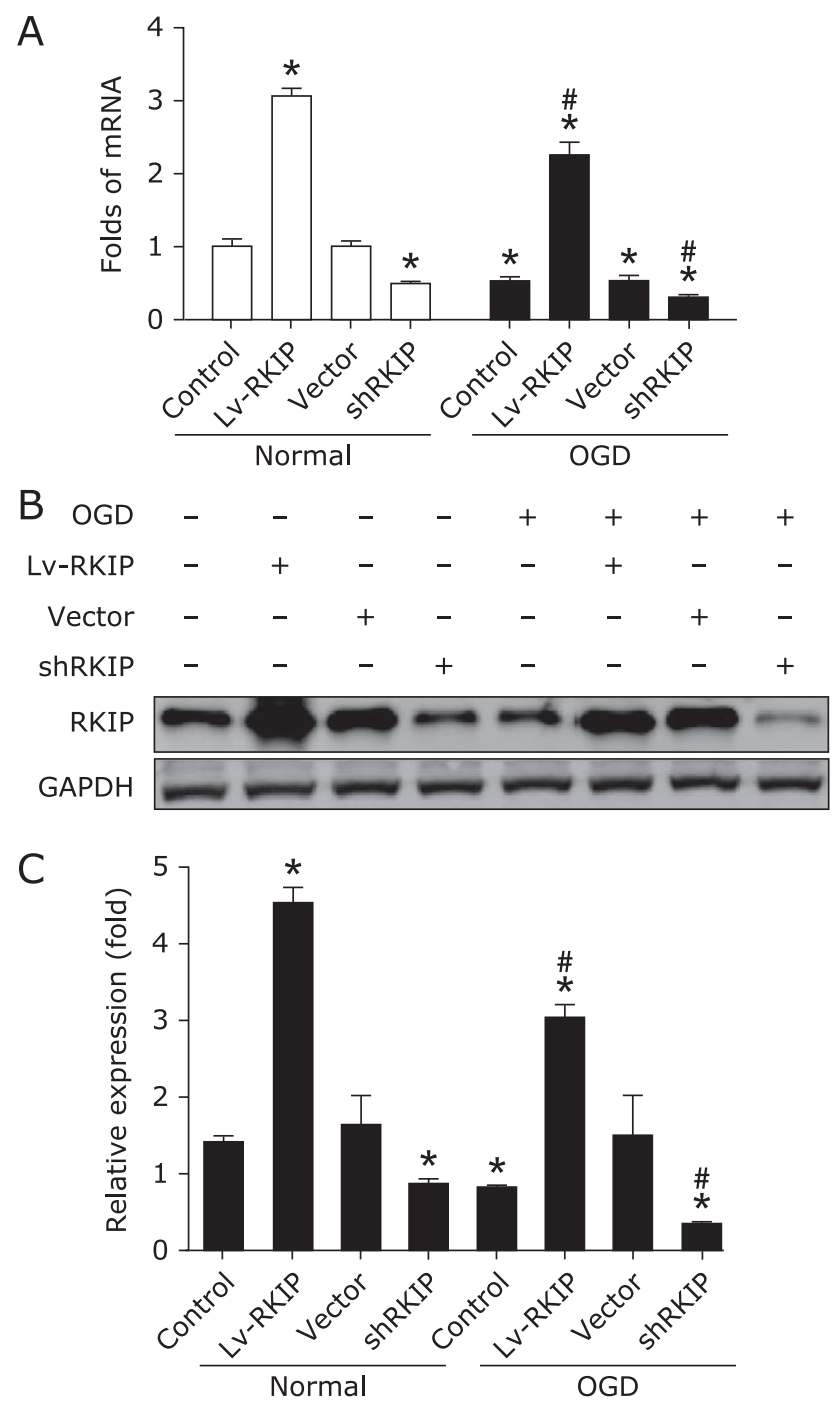

Fig. 1. The expression of RKIP in PC12 cells was determined by realtime PCR (A) and western blot (B) after OGD. GAPDH acted as the internal control. For real-time PCR and western blot, the data was from three independent experiments $(n=3)$, and quantitative comparisons (C) were made by densitometry relative to GAPDH. ${ }^{*} p<0.01$ vs control and ${ }^{\#} p<0.01$ vs OGD by one-way ANOVA analysis of variance with Tukey's HSD post hoc test.

GFP mixed with sh-Scramble, pLenti-RKIP-IRES-EGFP and pLenti6.3-EGFP-RKIP-microRNA, respectively. After $24 \mathrm{~h}$ incubation and replaced with fresh DMEM, PC12 cells were incubated for $48 \mathrm{~h}$ at $37^{\circ} \mathrm{C}$. Transduction efficiency was determined to be greater than $80 \%$ by measuring GFP.

Quantitative real-time PCR. Total RNA from PC12 cells was extracted using RNAiso Plus (Takara, Dalian, China) according to the manufacturer's protocol. One microgram of RNA was reverse transcribed to first strand cDNA, which was performed with Prime Script ${ }^{\mathrm{TM}}$ RT Master Mix (Takara), and then expression levels of mRNA was quantified by real-time PCR (Applied Biosystems, Foster City, CA) using SYBR premix Ex $\mathrm{Taq}^{\mathrm{TM}}$ (Takara). The program was included 1 cycle of $95^{\circ} \mathrm{C}$ for $5 \mathrm{~min}, 40$ cycles of $95^{\circ} \mathrm{C}$ for $10 \mathrm{~s}, 60^{\circ} \mathrm{C}$ for $30 \mathrm{~s}$ and $72^{\circ} \mathrm{C}$ for $20 \mathrm{~s}$. The results were calculated as the $2-\Delta \Delta^{\mathrm{CT}}$ values and house keeping gene is $\beta$-actin. The specific primers used for amplification were as follows: RKIP forward 5'-GACTACGGCGGAGTA ACGGTG-3', reverse 5'-GGGGTCCTTCCTGCTGGG-3'; Bcl-2 forward 5'-CGACTTTGCAGAGATGTCCA-3', reverse: 5'-ATG 
A

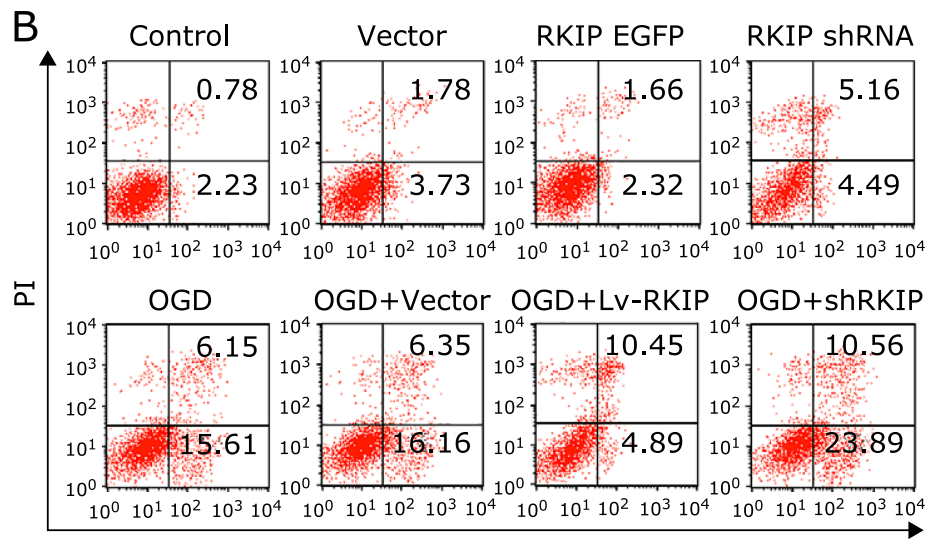

Annexin V-APC
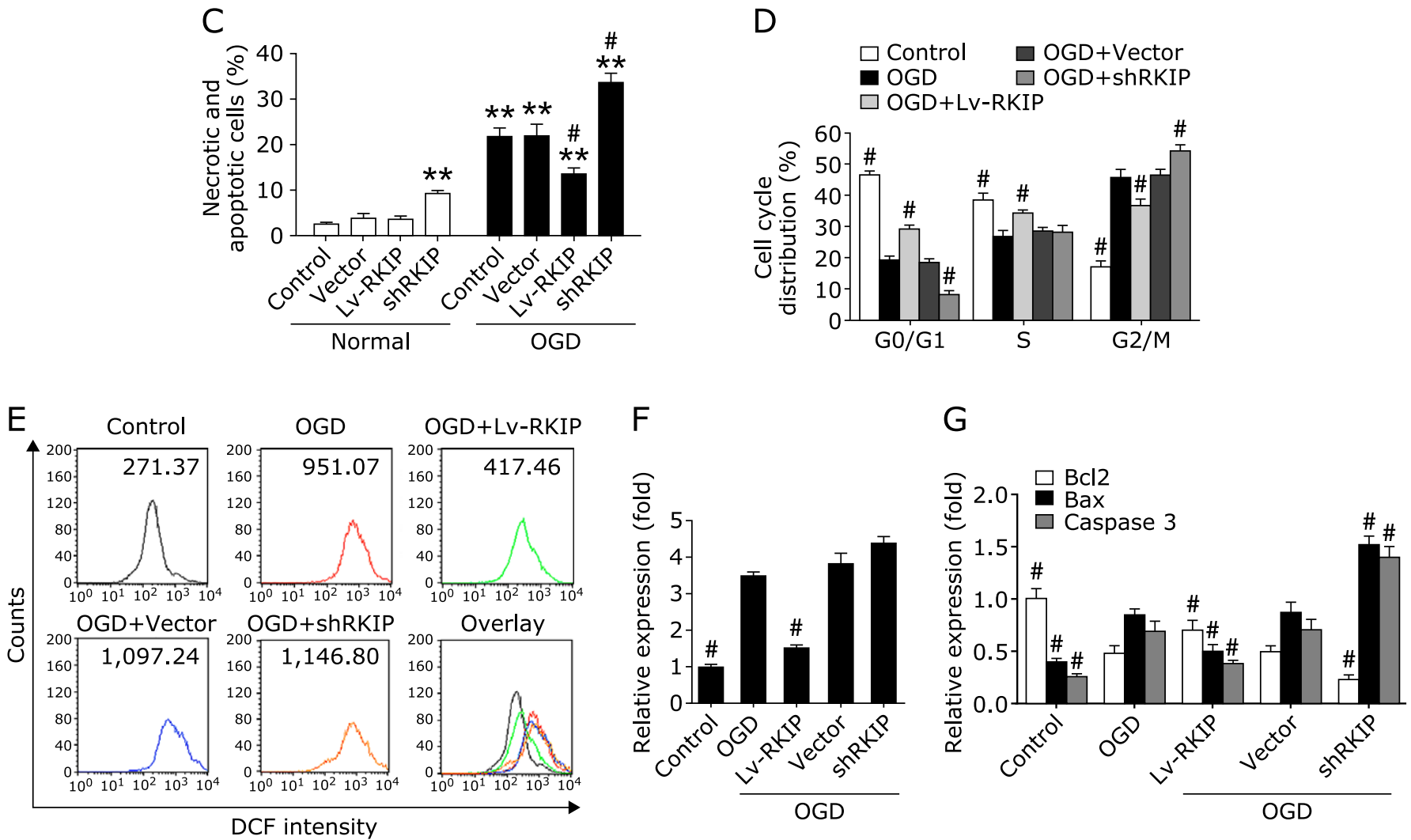

Fig. 2. RKIP regulated OGD-induced PC12 cells apoptosis. (A) The effect of RKIP overexpression and knockdown on the cell viability of normal and OGD-induced PC12 cells. (B, C) Apoptosis assay of RKIP overexpression and knockdown to OGD-induced PC12 cells by flow cytometry. (D) Cell cycle assay of RKIP overexpression and knockdown to OGD-induced PC12 cells by flow cytometry. (E, F) Effect of RKIP overexpression and knockdown on intracellular accumulation of ROS in OGD-induced PC12 cells. (G) Quantitative comparisons were made by densitometry relative to GAPDH. * $p<0.05$ and ${ }^{* *} p<0.01$ vs control and ${ }^{*} p<0.01$ vs OGD by one-way ANOVA analysis of variance with Tukey's HSD post hoc test.

CCGGTTCAGGTACTCAG-3'; Bax forward 5'-CTGCAGAGG ATGATTGCTGA-3', reverse: 5'-GATCAGCTCGGGCACTTT AG-3'; Caspase-3 forward 5'-GGACCTGTGGACCTGAAAAA3' reverse 5'-GCATGCCATATCATCGTCAG-3'; $\beta$-actin forward 5'-GGCACTCTTCCAGCCTTCC-3', reverse 5'-GAGCCGCCG ATCCACAC-3'.

Co-immunoprecipitation (Co-IP). PC12 cells proteins were extracted and quantified by a BCA kit (Pierce, Rockford, IL). For Co-IP, $400 \mu \mathrm{g}$ total protein was incubated with $5 \mu \mathrm{l}$ rabbit RKIP (Abcam, Cambridge, UK) antibody coated on protein A sepharose beads (Santa Cruz, CA) on roller at $4{ }^{\circ} \mathrm{C}$ overnight. After extensive wash, the beads were resuspended and boiled at $100^{\circ} \mathrm{C}$ for $5 \mathrm{~min}$, and then the supernatant were collected and detected by western blot for mouse NIK, TAK1, IKK, and Raf-1 (Santa Cruz) antibody. Simultaneously, mouse and rabbit IgG were used for negative control.

Western blot. PC12 Cells were washed with PBS and lysed with RIPA buffer containing $150 \mathrm{mM} \mathrm{NaCl}, 50 \mathrm{mM}$ Tris- $\mathrm{HCl}$ ( $\mathrm{pH} 7.8$ ), $0.25 \%$ sodium deoxycholate, $1 \% \mathrm{NP}-40$, and $1 \mathrm{mM}$ EDTA supplemented with protease inhibitors (Sigma, St. Louis, MO) and centrifuged at 12,000 RPM for $10 \mathrm{~min}$ as described previously. ${ }^{(21)}$ Protein concentration was determined by a BCA kit (Pierce, Rockford, IL) and electrophoresed on 10\% SDS polyacrylamide gels after boiling for $5 \mathrm{~min}$, and transferred to polyvinylidene difluoride (PVDF) membrane. Nonspecific reactivity was blocked by $5 \%$ nonfat milk prepared in TBST (10 mM Tris, 


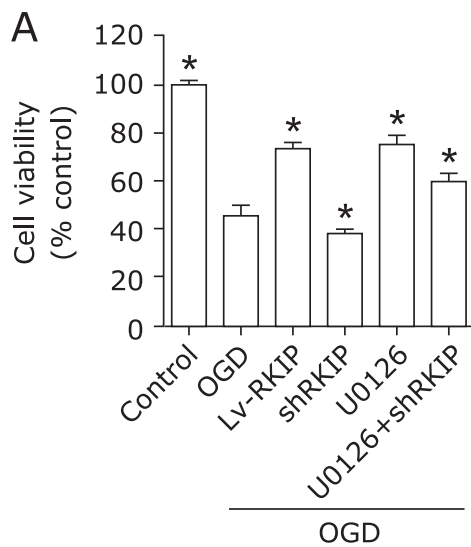

B
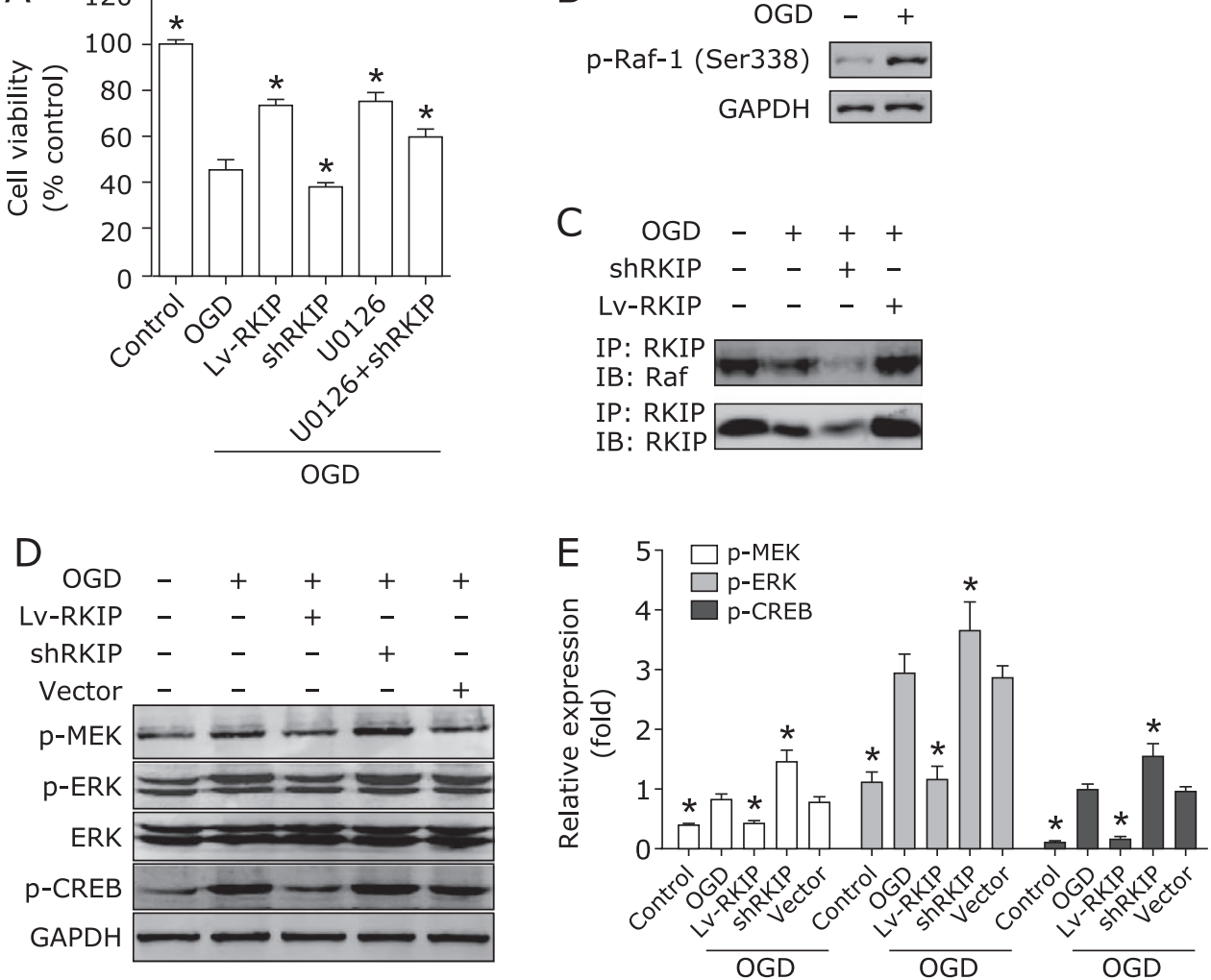

Fig. 3. RKIP regulates PC12 cells survival from OGD injury partly via ERK Pathway. (A) The effect of RKIP overexpression, knockdown and U0126 on the cell viability of normal and OGD-induced PC12 cells. (B) Raf-1 phosphorylation induced by OGD. (C) The interaction between RKIP and Raf-1 was detected by co-immunoprecipitation. (D) The expression of total MEK, ERK, and CREB and their phosphorylation was measured by western blot. (E) Quantitative comparisons of protein bands were analyzed by densitometry normalized to GAPDH. Data shown are the results of three different experiments. ${ }^{*} p<0.01$ vs OGD by one-way ANOVA analysis of variance with Tukey's HSD post hoc test.

$150 \mathrm{mM} \mathrm{NaCl}, 0.05 \%$ Tween-20, $\mathrm{pH} 7.5)$ for $1 \mathrm{~h}$. The membranes were incubated with RKIP (Abcam), ERK, p-MEK, p-ERK, and $\mathrm{p}-\mathrm{CREB}, \mathrm{p}-\mathrm{IKK} \beta, \mathrm{p}-\mathrm{I} \kappa \mathrm{B} \alpha, \mathrm{p}-\mathrm{P} 65$, and P65 (Cell Signaling, Danvers, MA) antibodies diluted according to the manufacturers' instructions. The image was captured by the Odyssey infrared imaging system (Li-Cor Bioscience, Lincoln, NE). Protein densitometry was scanned using Quantity One imaging software (Bio-Rad, Hercules, CA) and normalized to GAPDH.

Statistical analysis. Data were expressed as mean \pm SEM as indicated. The comparison between two groups was analyzed by unpaired Student $t$ test and multiple comparisons were compared by one-way ANOVA analysis of variance followed by Dunnett's test. $p<0.05$ was considered significant.

\section{Results}

OGD down-regulates RKIP in PC12 cells. Firstly, RKIP expression was determined in PC12 cells. Real-time PCR results demonstrated that RKIP mRNA was downregulated after OGD (Fig. 1A). Lentivirus overexpression (named Lv-RKIP) and interference (named shRKIP) significantly caused increase and decrease of RKIP mRNA expression, respectively. Western blot results showed RKIP overexpression after lentivirus-RKIP transfection. In contrast, RNA interference caused further decreases in RKIP expression after OGD. In addition, the Lenti-GFP and sh-Scramble vector (named vector) had not obvious effect on the expression of RKIP after exposure (Fig. 1B and C). Together, these results indicate the downregulation of RKIP and effective transfection of high differentiated PC12 cells with RKIP lentivirus after OGD.
RKIP protects PC12 cells from OGD-induced death. We further investigated the effect of RKIP on OGD-induced PC12 cells apoptosis. As shown in Fig. 2A, after treatment with shRKIP for $24 \mathrm{~h}$, the survival rate of PC12 cells was significantly reduced while RKIP overexpression significantly increased after OGD. Furthermore, RKIP overexpression significantly attenuated PC12 cells apoptosis, cell cycle arrest, and the generation of ROS while RKIP knockdown showed the reverse effect. Briefly, OGDinduced PC12 cells after RKIP knockdown displayed a cell apoptosis and cycle profile with an elevated necrotic and apoptotic cells rates $(34.36 \%$ and $21.82 \%$ for shRKIP and OGD-induced PC12 cells, respectively, as shown in Fig. 2B and C) and G2/M cell population $(54.10 \%$ and $45.59 \%$ for shRKIP and OGDinduced PC12 cells, respectively, as shown in Fig. 2D). Moreover, ROS generation in shRKIP group by flow cytometric analysis was significantly increased compared to the OGD group (Fig. 2E and F). Quantitative real-time PCR showed that the expression of caspase 3, Bax and Bcl-2 regulated by RKIP (Fig. 2G). Conversely, RKIP overexpression significantly decreased the apoptosis rates, G2/M cell population and ROS generation. In addition, the Lenti-GFP and sh-Scramble vector had no obvious effect on PC12 cells apoptosis after OGD. Together, these data indicated that RKIP regulates OGD-induced PC12 cells apoptosis.

RKIP protects PC12 cells survival from OGD injury partly via ERK Pathway. RKIP was reported as an inhibitor of the Raf/MEK/ERK pathway. We therefore used a specific inhibitor of MEK, U0126, to mimic the role of RKIP on ERK pathway in high differentiated PC12 Cells after OGD. U0126 $(5 \mu \mathrm{M})$ was added into cell cultures $30 \mathrm{~min}$ before OGD. The antagonism between MEK inhibitor U0126 and RKIP downexpression on cell survival 

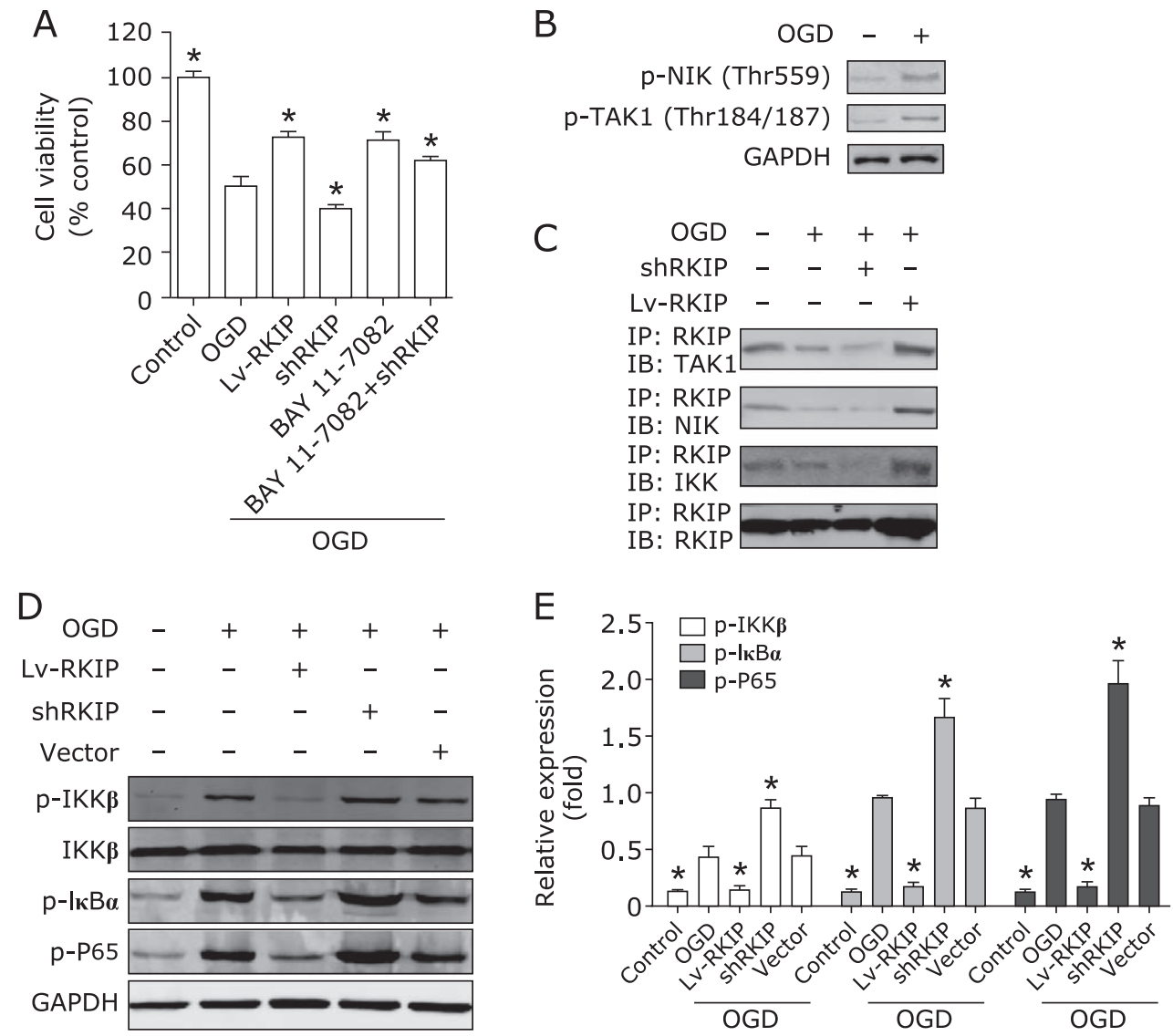

Fig. 4. RKIP regulates $P C 12$ cells survival induced by OGD partly via NF-KB Pathway. (A) The effect of RKIP overexpression, knockdown and BAY 117082 on the cell viability of normal and OGD-induced PC12 cells. (B) TAK1 and NIK phosphorylation induced by OGD. (C) The interaction between RKIP, TAK1, IKK, and NIK was detected by co-immunoprecipitation. (D) The phosphorylation expression of IKK $\beta$, IKB $\alpha$, and P65 were measured by western blot. (E) Quantitative comparisons of protein bands were analyzed by densitometry normalized to GAPDH. Data shown are the results of three different experiments. ${ }^{*} p<0.01$ vs OGD by one-way ANOVA analysis of variance with Tukey's HSD post hoc test.

caused by OGD was examined. After OGD, the survival rate was substantially decreased in high differentiated PC12 cells (Fig. 3A). RKIP overexpression and U0126 significantly increased the survival rate of PC12 cells induced by OGD. Furthermore, OGD induced Raf-1 phosphorylation (Fig. 3B). Moreover, RKIP interacts with Raf-1 and their interaction was attenuated after OGD (Fig. 3C). The phosphorylation of MEK, ERK, and CREB were increased obviously, indicating that ERK and CREB signaling pathways are excessively activated by OGD. RKIP overexpression increased the interaction between RKIP and Raf-1 and inhibited the upregulation of phosphorylation of MEK, ERK, and CREB induced by OGD. Conversely, RKIP downregulation further attenuated the interaction between RKIP and Raf- 1 and promoted the activation of ERK and CREB pathways. In addition, the LentiGFP and sh-Scramble vector had no obvious effect (Fig. 3D and E). Altogether, these results show that inhibition of the ERK pathway by RKIP is attenuated after OGD, resulting in excessive activation of the MEK/ERK/CREB pathway and RKIP regulates PC12 cells survival induced by OGD partly via ERK Pathway.

Regulation on NF-KB pathway by RKIP contributes to its neuroprotection in PC12 cells after OGD. We also investigated the role of RKIP on NF- $\kappa B$ pathway. RKIP overexpression and BAY 11-7082, a specific inhibitor of NF- $\kappa B$, significantly increased the survival rate of OGD induced PC12 cells (Fig. 4A). Furthermore, OGD induced NIK and TAK1 phosphorylation (Fig. 4B). RKIP interacts with TAK1, IKK, and NIK, respectively, and their interaction was attenuated after OGD (Fig. 4C).
Moreover, the phosphorylation of IKK $\beta$, I $\kappa \mathrm{B} \alpha$, and P65 were increased obviously, indicating that NF- $\kappa \mathrm{B}$ is excessively activated by OGD. RKIP overexpression increased their interaction and inhibited the upregulation of phosphorylation of $N F-\kappa B$ induced by OGD. Conversely, RKIP downregulation further attenuated the interaction and promoted the activation of NF- $\mathrm{BB}$ pathway (Fig. 4D and E). Taken together, the results demonstrate that regulation of cell apoptosis by RKIP is partly dependent on the NF- $\kappa \mathrm{B}$ pathway.

\section{Discussion}

RKIP has been identified as an inhibitor of the NF- $\kappa \mathrm{B}$ and Raf/ MEK/ERK pathways. ${ }^{(8)}$ By regulating ERK and NF- $\kappa B$ pathways, RKIP affects various cellular processes including cell differentiation, cell cycle, apoptosis, and cell migration. ${ }^{(7,25)} \mathrm{NF}$ $\kappa \mathrm{B}$ and ERK pathways are known to alter the expression of pro-apoptotic and anti-apoptotic genes such as Bax and Bcl-2 by regulating the activity of CREB transcription factors. ${ }^{(26,27)}$ Therefore, RKIP is considered to play a pivotal role in apoptosis, but it is not clear at present how RKIP may regulate apoptosis in cerebral ischemia.

In this study, we found that the NF- $\kappa \mathrm{B}$ and ERK pathways regulated by RKIP play an important role in neural cell apoptosis induced by OGD, although other pathways may also likely to be involved in this process. These results suggest that downregulation of RKIP may shift the balance from anti-apoptotic to pro- 
apoptotic signaling pathways after OGD, which results in a decrease in the Bcl-2/Bax ratio and activation of caspase-3, triggering the execution of apoptosis. According to the present findings, BAY 11-7082 and U0126 can protect PC12 cells induced by OGD, which further indicates that the NF- $\kappa \mathrm{B}$ and ERK pathways play a pro-apoptotic role in OGD-induced apoptosis of neural cells. These results were in agreement with a recent report about the role of ERK pathway in cell apoptosis. ${ }^{(14)}$

Previous report has shown that the activated ERK and NF- $\kappa \mathrm{B}$ may act as a pro-apoptotic factor, although it has been described as an anti-apoptotic factor in several cellular models. ${ }^{(28,29)}$ Much evidence indicates that the long-term activation of ERK and NF$\kappa \mathrm{B}$ pathways can induce neural cells apoptosis. ${ }^{(30-32)}$ Furthermore, activation of the ERK and NF- $\kappa$ B pathways has been proved to be one of the early characteristics of neuronal degeneration diseases. ${ }^{(33-35)}$ Moreover, RKIP has been thought to be important for the proliferation and differentiation of neural cells in vitro and in vivo by modification of the MAPK cascade. As a precursor to HCNP, RKIP can affect neuronal choline acetyl-transferase. Cholinergic dysfunction of the brain is known to be associated with age-related memory loss, one of the symptoms that is particularly characteristic of AD. ${ }^{(36)}$ Significant decreases in RKIP expression levels have been documented in the brains of AD patients and the mouse model. ${ }^{(17,18)}$ Thus, it is conceivable that the loss of RKIP in the brain favors neuronal degeneration and cholinergic dysfunction. In the present study, RKIP knockdown lead to PC12 cells death after OGD and may further cause neuronal degeneration. Therefore, RKIP overexpression may be a therapeutic strategy for neuronal injury caused by OGD. Furthermore, these results show that RKIP can protect high differentiated PC12 cells from apoptosis induced by OGD, which is different from its pro-apoptotic role in cancer research. It has been proved that RKIP sensitized drug-resistant tumor cells to drug-induced apoptosis. ${ }^{(37)}$ Moreover, emerging data suggests that RKIP is a potential bio-marker for the neurodegenerative diseases and prognosis of carcinoma, and its dysregulation might play an important role in the some cancer cells. ${ }^{(38-40)}$ Overall, this study may provide insights into the role of RKIP in neuronal apoptosis in ischemic stroke. Further studies are necessarily needed to elucidate the exact mechanism of action of RKIP in cell apoptosis.

\section{Conclusions}

In summary, the present study demonstrates that downregulation of RKIP results in the excessive activation of the NF- $\kappa \mathrm{B}$ and

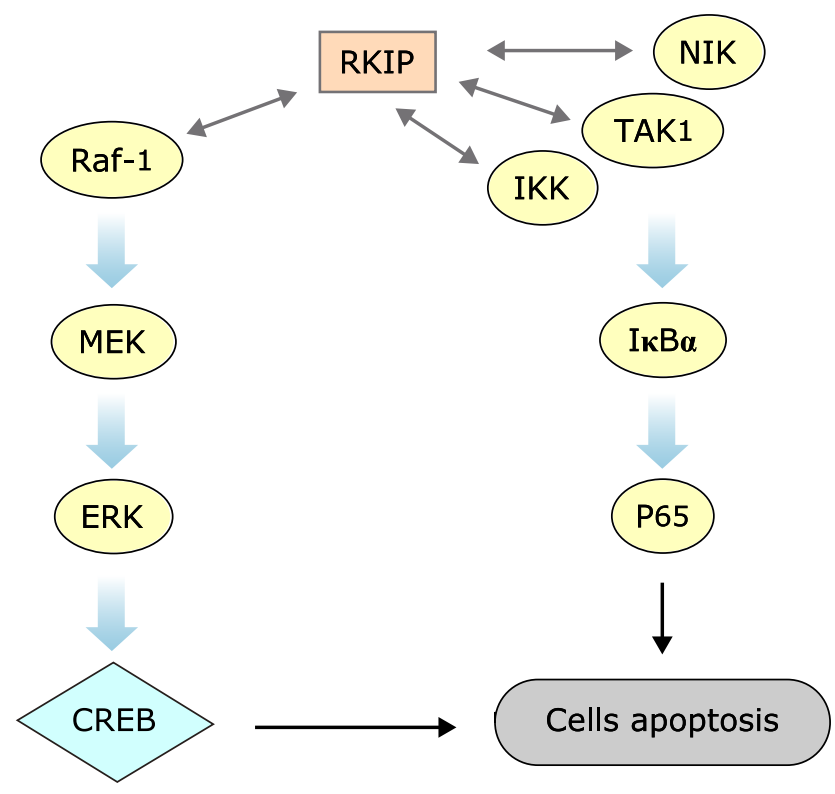

Fig. 5. Schematic form of the proposed mechanisms for RKIP regulated OGD-induced PC12 cells apoptosis. RKIP binds to Raf-1, TAK1, IKK, and NIK, inhibiting activation of ERK and NF-KB pathways.

ERK pathways and finally triggering the execution of apoptosis in high differentiated PC12 cells after OGD (Fig. 5). The present study provides a mechanism of regulating neuronal apoptosis for RKIP. Namely, RKIP regulates neural cell apoptosis induced by OGD partly through the NF- $\kappa \mathrm{B}$ and ERK pathways. These results further indicate that RKIP may serve as a key regulator of neuronal injury caused by OGD.

\section{Acknowledgments}

The work was supported by the Natural Science Foundation of China (81202532).

\section{Conflict of interest}

No potential conflicts of interest were disclosed.

\section{References}

1 Mozaffarian D, Benjamin EJ, Go AS, et al:; American Heart Association Statistics Committee and Stroke Statistics Subcommittee. Heart disease and stroke statistics--2015 update: a report from the American Heart Association. Circulation 2015; 131: e29-e322.

2 Martin R, Lloyd H, Cowan A. The early events of oxygen and glucose deprivation: setting the scene for neuronal death? Trends Neurosci 1994; 17: 251257.

3 Badiola N, Penas C, Miñano-Molina A, et al. Induction of ER stress in response to oxygen-glucose deprivation of cortical cultures involves the activation of the PERK and IRE-1 pathways and of caspase-12. Cell Death Dis 2011; 2: e149.

4 Sawe N, Steinberg G, Zhao H. Dual roles of the MAPK/ERK1/2 cell signaling pathway after stroke. J Neurosci Res 2008; 86: 1659-1669.

5 Chen $\mathrm{X}$, Chen S, Jiang $\mathrm{Y}$, et al. Minocycline reduces oxygen-glucose deprivation-induced $\mathrm{PC} 12$ cell cytotoxicity via matrix metalloproteinase-9, integrin $\beta 1$ and phosphorylated Akt modulation. Neurol Sci 2013; 34: 13911396.

6 Keller ET, Fu Z, Brennan M. The role of Raf kinase inhibitor protein (RKIP) in health and disease. Biochem Pharmacol 2004; 68: 1049-1053.

7 Al-Mulla F, Bitar MS, Taqi Z, Yeung KC. RKIP: much more than Raf kinase inhibitory protein. J Cell Physiol 2013; 228: 1688-1702.

8 Yeung $\mathrm{KC}$, Rose DW, Dhillon AS, et al. Raf kinase inhibitor protein interacts with NF- $\kappa \mathrm{B}$-inducing kinase and TAK1 and inhibits NF- $\kappa \mathrm{B}$ activation. Mol Cell Biol 2001; 21: 7207-7217.

9 Yeung K, Janosch P, McFerran B, et al. Mechanism of suppression of the Raf/MEK/extracellular signal-regulated kinase pathway by the raf kinase inhibitor protein. Mol Cell Biol 2000; 20: 3079-3085.

10 Yeung K, Seitz T, Li S, et al. Suppression of Raf-1 kinase activity and MAP kinase signalling by RKIP. Nature 1999; 401: 173-177.

11 Tang H, Park S, Sun SC, et al. RKIP inhibits NF-kB in cancer cells by regulating upstream signaling components of the IкB kinase complex. FEBS Lett 2010; 584: 662-668.

12 Yesilkanal AE, Rosner MR. Raf kinase inhibitory protein (RKIP) as a metastasis suppressor: regulation of signaling networks in cancer. Crit Rev Oncog 2014; 19: 447-454.

13 Trakul N, Rosner MR. Modulation of the MAP kinase signaling cascade by Raf kinase inhibitory protein. Cell Res $2005 ; 15$ : 19-23.

14 Zuo H, Lin T, Wang D, et al. RKIP regulates neural cell apoptosis induced by exposure to microwave radiation partly through the MEK/ERK/CREB pathway. Mol Neurobiol 2015; 51: 1520-1529. 
15 Ling HH, Mendoza-Viveros L, Mehta N, Cheng HY. Raf kinase inhibitory protein (RKIP): functional pleiotropy in the mammalian brain. Crit Rev Oncog 2014; 19: 505-516.

16 Maki M, Matsukawa N, Yuasa H, et al. Decreased expression of hippocampal cholinergic neurostimulating peptide precursor protein mRNA in the hippocampus in Alzheimer disease. J Neuropathol Exp Neurol 2002; 61: 176-185.

17 George AJ, Gordon L, Beissbarth T, et al. A serial analysis of gene expression profile of the Alzheimer's disease Tg2576 mouse model. Neurotox Res 2010; 17: 360-379.

18 George AJ, Holsinger RD, McLean CA, et al. Decreased phosphatidylethanolamine binding protein expression correlates with $A \beta$ accumulation in the Tg2576 mouse model of Alzheimer's disease. Neurobiol Aging 2006; 27: 614-623.

19 Guo J, Wu HW, Hu G, Han X, De W, Sun YJ. Sustained activation of Srcfamily tyrosine kinases by ischemia: a potential mechanism mediating extracellular signal-regulated kinase cascades in hippocampal dentate gyrus. Neuroscience 2006; 143: 827-836.

20 Liu Y, Song XD, Liu W, Zhang TY, Zuo J. Glucose deprivation induces mitochondrial dysfunction and oxidative stress in PC12 cell line. J Cell Mol Med 2003; 7: 49-56.

21 Yue R, Yuan X, Liu X, et al. Cynandione A mitigates ischemic injuries in rats with cerebral ischemia. $J$ Neurochem 2012; 121: 451-464.

22 Wang P, Xu TY, Guan YF, et al. Nicotinamide phosphoribosyltransferase protects against ischemic stroke through SIRT1-dependent adenosine monophosphate-activated kinase pathway. Ann Neurol 2011; 69: 360-374.

23 Yue Q-X, Cao Z-W, Guan S-H, et al. Proteomics characterization of the cytotoxicity mechanism of ganoderic acid D and computer-automated estimation of the possible drug target network. Mol Cell Proteomics 2008; 7: 949961.

24 Qin JY, Zhang L, Clift KL, et al. Systematic comparison of constitutive promoters and the doxycycline-inducible promoter. PloS One 2010; 5: e10611.

25 Zeng L, Imamoto A, Rosner MR. Raf kinase inhibitory protein (RKIP): a physiological regulator and future therapeutic target. Expert Opin Ther Targets 2008; 12: 1275-1287.

26 Chen C, Edelstein LC, Gélinas C. The Rel/NF-кB family directly activates expression of the apoptosis inhibitor Bcl- $\mathrm{x}_{\mathrm{L}}$. Mol Cell Biol 2000; 20: $2687-$ 2695 .
27 Czabotar PE, Lessene G, Strasser A, Adams JM. Control of apoptosis by the BCL-2 protein family: implications for physiology and therapy. Nat Rev Mol Cell Biol 2014; 15: 49-63.

28 Kolch W. Coordinating ERK/MAPK signalling through scaffolds and inhibitors. Nat Rev Mol Cell Biol 2005; 6: 827-837.

29 DiDonato JA, Mercurio F, Karin M. NF- $\kappa$ B and the link between inflammation and cancer. Immunol Rev 2012; 246: 379-400.

30 Newbern JM, Li X, Shoemaker SE, et al. Specific functions for ERK/MAPK signaling during PNS development. Neuron 2011; 69: 91-105.

31 Deschênes-Simard X, Gaumont-Leclerc M-F, Bourdeau V, et al. Tumor suppressor activity of the ERK/MAPK pathway by promoting selective protein degradation. Genes Dev 2013; 27: 900-915.

32 Perkins ND. The diverse and complex roles of NF- $\kappa \mathrm{B}$ subunits in cancer. Nat Rev Cancer 2012; 12: 121-132.

33 Klysik J, Theroux SJ, Sedivy JM, Moffit JS, Boekelheide K. Signaling crossroads: the function of Raf kinase inhibitory protein in cancer, the central nervous system and reproduction. Cell Signal 2008; 20: 1-9.

34 Pei JJ, Braak H, An WL, et al. Up-regulation of mitogen-activated protein kinases ERK1/2 and MEK1/2 is associated with the progression of neurofibrillary degeneration in Alzheimer's disease. Mol Brain Res 2002; 109: 45 55.

35 Granic I, Dolga AM, Nijholt IM, van Dijk G, Eisel UL. Inflammation and NF-кB in Alzheimer's disease and diabetes. J Alzheimers Dis 2009; 16: 809821.

36 Ojika K, Mitake S, Tohdoh N, et al. Hippocampal cholinergic neurostimulating peptides (HCNP). Prog Neurobiol 2000; 60: 37-83.

37 Chatterjee D, Bai Y, Wang Z, et al. RKIP sensitizes prostate and breast cancer cells to drug-induced apoptosis. J Biol Chem 2004; 279: 17515-17523.

38 Al-Mulla F, Bitar MS, Al-Maghrebi M, et al. Raf kinase inhibitor protein RKIP enhances signaling by glycogen synthase kinase-3 $\beta$. Cancer Res 2011; 71: 1334-1343.

39 Yousuf S, Duan M, Moen EL, et al. Raf kinase inhibitor protein (RKIP) blocks signal transducer and activator of transcription 3 (STAT3) activation in breast and prostate cancer. PLoS One 2014; 9: e92478.

40 Fu Z, Kitagawa Y, Shen R, et al. Metastasis suppressor gene Raf kinase inhibitor protein (RKIP) is a novel prognostic marker in prostate cancer. Prostate 2006; 66: 248-256. 